\title{
LETTERS
}

\section{Relationship Between Distal and Proximal Neoplasia}

\author{
Levent Filik \\ Gastroenterology Clinic, Ankara Research Hospital, Ankara, Turkey.
}

(c) Society of General Internal Medicine 2012

To the Editor:- In their recent article, Dodou and de Winter underlined that all types of distal lesions are predictive of proximal neoplasia (PN). ${ }^{1}$ This conclusion is especially important for colorectal cancer screening. If so, colonoscopy should be performed instead of flexible rectosigmoidoscopy. Risk of advanced proximal colon neoplasm progressing to fatal cancer is relatively low ( $1 \%$ per year). ${ }^{2,3}$ On the other hand we must remember that lesions can be missed even in colonoscopy especially flat ones that may progress more rapidly to cancer.

Published online May 2, 2012
Cost of colonoscopy is another issue of concern for patients with distal lesions.

Corresponding Author: Levent Filik, Gastroenterology Clinic, Ankara Research Hospital, Ankara 06600, Turkey (e-mail: leventfilik@yahoo.co.uk).

\section{REFERENCES}

1. Dodou D, de Winter JCF. The Relationship Between Distal and Proximal Colonic Neoplasia: A Meta-Analysis. JGIM 2012;27:361-370.

2. Ransohoff DF. Lessons from the UK sigmoidoscopy screening trial. Lancet. 2002;359(9314):1266-7.

3. Eide TJ. Risk of colorectal cancer in adenoma bearing individuals within a defined population. Int $J$ Cancer 1986;38(2):173-6. 